prevalence cross-product ratio, and that the latter is the measure that consistently yields an appropriate measure of the Incidence Density Ratio. Debating the role of multivariate regression models in cross-sectional studies, we contend that such models should be avoided when the structuring assumptions for causal inference do not hold. Nevertheless, if these assumptions are reasonably met, it is the logistic regression model that is best suited for this task as it provides a suitable estimate of the Incidence Density Ratio.

Discussion In closing, we discuss the (un)favourable arguments raised in the literature in the light of our findings.

\section{P1-499 PREVALENCE AND ASSOCIATED FACTORS OF ANTERIOR OPEN BITE IN CHILDREN AGED 2-5 YEARS-OLD}

doi:10.1136/jech.2011.142976g.87

${ }^{1} \mathrm{C}$ R da S Castro, ${ }^{* 2}$ M I P Vianna, ${ }^{2}$ M C T Cangussu. ${ }^{1}$ Instituto de Saúde Coletiva, Salvador, Bahia, Brazil; ${ }^{2}$ Faculdade de Odontologia da UFBA, Salvador, Bahia, Brazil

Introduction The anterior open bite is the malocclusion with major aesthetic and functional commitments, besides it has a more complex treatment. In order to prevent its occurrence, it's fundamental to know the risk factors.

Objective To estimate the prevalence of anterior open bite and to examine the effects of some variables such as behaviours and those related to familiar environment.

Methods A cross-sectional study was carried out in Salvador-BA, in 2005. A sample of 362 children aged between 2 and 5 years old was examined and their relatives were interviewed in their homes. The Self-Report Questionnaire (SOR-20) and CAGE scale (adaptated) were used to report psychiatric symptoms and alcoholism in the family. Descriptive analysis was proceeded. In order to verify the associations, OR, adjusted for the independent variables, was estimated through of non-conditional logistic regression.

Results The prevalence of anterior open bite was $19.19 \%$. Results of the logistic analysis showed a positive association between nonnutritive sucking habits and anterior open bite in children $\left(\mathrm{OR}_{\mathrm{ajust}}=7.44 ; 95 \%\right.$ CI 3.30 to 16.74$)$. There was no association between familiar dysfunction, referred to the presence of psychiatric symptoms and alcoholism in the family, and anterior open bite.

Conclusions Results suggest that there is, in the population studied, an association between sucking behaviour and the occurrence of anterior open bite in children. The knowledge of malocclusion in the primary dentition favours preventive actions to reduce the prevalence of malocclusion.

\section{P1-500 INFLUENCE OF DURATION OF BREASTFEEDING IN THE ORAL HABITS AND MALOCCLUSION IN CHILDREN}

doi:10.1136/jech.2011.142976g.88

${ }^{1} \mathrm{C}$ R da S Castro, ${ }^{*}$ M I P Vianna, ${ }^{3} \mathrm{~A}$ de Carvalho Gonçalves. ${ }^{1}$ Instituto de Saúde Coletiva, Salvador, Bahia, Brazil; ${ }^{2}$ Faculdade de Odontologia da UFBA, Salvador, Bahia, Brazil, ' Universidade Federal do Rio Grande do Sul, Porto Alegre, Rio Grande do Sul, Brazil

Breast milk is the ideal food for infants by providing nutrients for their development and providing protection against infection, in addition to the psychological benefits arising from the mother-child involvement. Regarding oral health, breastfeeding has been associated with adequate growth and development of the maxillomandibular. The objectives of this study was to investigate the association between duration of breastfeeding, harmful habits and malocclusion, as well as investigate the association between these habits and malocclusion. We conducted a cross-sectional study with children ages $2-5$ years in areas covered by the PSF and PACS in the city of Salvador, Bahia in 2005. We carried out the diagnosis of malocclusions in children and was administered to mothers, a questionnaire on breastfeeding duration and oral habits. We conducted a descriptive analysis of variables of interest and stratified crude associations were estimated by prevalence ratios and CIs at $95 \%$, obtained by the Mantel-Haenszel method. The prevalence of malocclusion was $39.5 \%$. Of children breastfed for $<6$ months, $74.2 \%$ had oral habits and $51.6 \%$ malocclusion. An association between short duration of breastfeeding and presence of deleterious sucking habits ( $\mathrm{PR}=1.97$, CI 1.59 to 2.45 ), as well as the occurrence of malocclusion ( $\mathrm{PR}=1.54, \mathrm{CI} 1.16$ to -2.03 ). The association between sucking habits and malocclusion was statistically significant ( $\mathrm{PR}=2.31$, CI 1.67 to 3.22 ). We stress the importance of encouraging breastfeeding for over 6 months and discourage the use of pacifiers, aiming preventing the occurrence of malocclusions.

\section{P1-501 FUNCTIONAL PERFORMANCE AMONG THE ELDERLY AND QUALITY OF URBAN LIFE IN BELO HORIZONTE, MINAS GERAIS, BRAZIL: A MULTILEVEL ANALYSIS}

doi:10.1136/jech.2011.142976g.89

F R Ferreira, ${ }^{*}$ C C César, M F Lima-Costa, V P Camargo, F A Proietti. UFMG, Belo Horizonte, Minas Gerais, Brazil

Introduction There is an increasing interest about the influence of the environment on people living in urban areas. Elderly are more vulnerable to changes in the physical and social environment associated to urbanisation. The neighbourhood has an important role in maintaining independence.

Methods We adopted the theoretical model of causal effects of neighbourhood on ageing of Glass \& Balfour. The study included 1155 elderly ( $\geq 60$ years) selected by random sampling. Response variable "functional performance" was developed based on the number of basic and instrumental activities of daily living (ADL) that the elderly found difficult to accomplish. Urban Quality of Life Index (UOLI) was used as the second-level variable. The UOLI domains assume values between zero and one (zero = worst situation; one $=$ the best) Zero-inflated negative binomial multilevel regression model (ZINB Multilevel) was used in the statistical analysis.

Results Functional performance is influenced by urban infrastructure, one of the UOLI domains. Living in a neighbourhood with a infrastructure index $\geq 0.80$ increased by 4.2 times the chance of the elderly to be independent when compared with those living in neighbourhoods with an index $<0.80$, after controlling for individual level variables. The interclass correlation coefficient for the secondlevel domain was 0.17 , indicating that $17.0 \%$ of the variance in functional performance of the elderly may be explained by differences in the infrastructure of the BHMPU.

Conclusion Public intervention programs aiming an improvement in the performances of the elderly must take into account the contribution of urban infrastructure in the neighbourhood.

\section{P1-502 PSYCHOSOCIAL FACTORS, MENOPAUSE CHARACTERISTICS, PHYSICAL AND MENTAL MORBIDITY AND THEIR ASSOCIATION WITH INSOMNIA COMPLAINTS AMONG WOMEN IN MENOPAUSE. THE PRÓ-SAÚDE STUDY}

doi:10.1136/jech.2011.142976g.90

1J R Robaina, ${ }^{*} \mathrm{C}$ de Souza Lopes, ${ }^{2}$ L Rotenberg. 'Universidade do Estado do Rio de Janeiro, Rio de Janeiro, Rio de Janeiro, Brazil; ${ }^{2}$ Fundação Oswaldo Cruz, Rio de Janeiro, Rio de Janeiro, Brazil

Menopausal women have a higher prevalence of insomnia. Despite the vast literature, several aspects are still controversial or have 